failure of the heart to cope with a normal inflow of blood (cardiac syncope). In many faints both factors come into play, and the attacks are known as vaso-vagal attacks. Where, however, vagal inhibition is the chief factor, the term "vago-vagal attack" has been used. At this time of life such attacks are probably due to degenerative changes in the cardiovascular system, though it may be difficult to discover whether the chief lesion is in the heart, the peripheral vessels, or the cerebral circulation. The effects of pressure on the carotid sinus should be examined to exclude the cardiac type of carotid sinus syncope. The oesophagus and stomach should be examined radiologically, as diverticula, pouches, aerophagy, etc., may produce vagus inhibition. Stokes-Adams syndrome is unlikely in view of the moderate degree of slowing of the pulse and the cardiologist's report. The fasting blood sugar should be estimated to exclude spontaneous hypoglycaemia. If these investigations prove negative treatment may be attempted with atropine or belladonna, in full doses, or with ephedrine. Digitalis must be avoided and smoking should be given up. The advice to take a holiday also seems sound, as vagal inhibition may be the result of reflexes which are more likely to be overactive when the patient is tired.

\section{Control of Petit Mal}

Q.-What is the latest treatment of petit mal, and is it possible to control the attacks now? I have a patient aged 14, a girl, who has had them since she was 5; luminal does not seem to have any beneficial results.

A.- There has been no advance in the treatment of petit mal in the past few years. Bromides and phenobarbital remain the drugs of choice. It is general experience that the hydantoins (epanutin) do not benefit patients with petit mal, although they are very efficacious in many cases of grand mal. Occasionally, however, a patient with petit mal responds well to epanutin, which can be used with advantage in combination with luminal. For a girl of 14 luminal gr. $1 / 2$ t.d.s. with a capsule of epanutin $(0.1 \mathrm{~g}$. $)$ should be adequate, but smaller doses might be satisfactory. Dietetic treatment has been discarded by most neurologists now, for the results did not justify the labour and discomfort, and in any case the high fat diet is impracticable in wartime.

\section{Congo Red for Haemoptysis}

Q. -What is the rationale of the use of Congo red in the treatment of haemoptysis?

A.-Congo red is used in the treatment of haemoptysis because it is said to reduce the clotting time of the blood. It was recommended for this purpose by Wedekind, Becker, and Weinert (Münch. med. Wschr., 1930, 78, 2049). Its use was described by Morlock and Pinchin in this Journal (1934, 2, 762). They gave intravenously $10 \mathrm{c} . \mathrm{cm}$. of a $1 \%$ solution of specially purified Congo red. They state that the injection causes an increase in the monocytes, an increase in the platelets, and an increase in the blood fibrin, as well as a reduction in clotting time. The injection is believed to stimulate the cells of the reticulo-endothelial system. Sometimes the patient has a rigor soon after the injection, but it is stated that this is never severe enough to cause alarm.

\section{Interpretation of G.C.F.T.}

Q.-What conclusions can one draw from a positive gonococcal complement-fixation test? One of my pilots is completely asympto matic without suggestive history, but has such a positive reaction. One of his friends was having a premarital check-up, and he had his blood taken for G.C.F.T. and W.R. at the same time. The pathological report is positive " + \pm ," presumably not indicating a very strong reaction. Can other infections-e.g., allied Neisserian (meningococcal), or quite unrelated non-specific venereal infections, or even non-infectious disease, give rise to a positive result? Finally, what is one at liberty to deduce from a negative gonococcal complement-fixation test?

A.- In general the result of a gonococcal complement-fixation test is to be interpreted in much the same way as that of a W.R. a diagnosis of gonorrhoea should not be founded on a single positive G.C.F.T. any more than one of syphilis should be on a single positive W.R. In the case in question it would be well to have the test repeated, and if it is still positive to advise a clinical overhaul by an experienced venereologist. It has been established that other Neisserian infections, and especially that with $N$ catarrhalis, do occasionally give rise to false positive G.C.F.T.s; there is no evidence that non-specific venereal infections or non-infectious diseases give rise to such reactions. The G.C.F.T. is negative in the early stages of gonorrhoea, usually becomes positive after a week or two if the disease is not treated, and returns to negative at varying times after cure, depending on the length of time the disease has existed, the presence or absence of complications, and whether vaccine has been used or not. A negative test is of especial value as a test of cure if it has previously been positive; it is also of considerable value in the differential diagnosis of cases of epididymitis, prostatitis, arthritis, etc., of obscure origin; where these are due to the gonococcus the test is nearly always positive.

The above remarks apply only to tests carried out in a reliable laboratory; the number of laboratories in this country where reliable G.C.F.T.S are carried out is very limited, mainly owing to the difficulty of obtaining a suitable antigen.

\section{INCOME TAX}

\section{Benefits in Kind}

M. S. employs a surgery cleaner whom he supplies with dinners and teas; can he charge the cost of the meals as a professional expense?

${ }_{*}^{*}$ Certainly. As to the amount to be charged, it is not possible to give advice other than to say that a reasonable estimate of the cost of the food should be the basis of the amount which can be charged

\section{Partner Serving Abroad}

" $Z$ 's" partner is serving in India, and his pay is taxed there. The firm is in the Isle of Man and the partnership arrangement provides that the pay shall be brought into the partnership account for division on the normal basis with the two other partners. Income tax is claimed on this pay by the Isle of Man authorities.

${ }_{*}^{*}$ We do not think the claim is justified. The pay is not normally regarded as liable to income tax in the country of residence, and we do not think it becomes liable because it is subsequently divided with others. It would be stretching the argument too far to contend that the earnings of an Army officer in India are part of the profits of a practice carried on in the Isle of Man.

\section{"Pay as you Earn"}

J. H. holds an appointment in an institution. The scales of salary were increased in April, 1944, with effect as from May 15, 1943 In consequence he received last May an additional payment of $£ 125$, from the whole of which income tax was deducted under "pay as you earn." Should he not have the benefit of the $7 / 12$ ths cancellation to the extent to which the $£ 125$ was earned before April 6, 1944.

** It should be borne in mind that "pay as you earn" is a system of collection of tax, and (with the important exceptions that 7/12ths of the 1943-4 tax is cancelled and that the current year's earnings are now the basis of assessment) does not affect the way in which the ultimate liability for any year is calculated. When J. H.'s earnings for 1944-5 are assessed (sometime after April 5, 1945) the appropriate part of the $£ 125$ will be regarded as assessable for 1943-4 and the tax for that year will be recalculated. The result will presumably be to show that $\mathbf{J}$. $\mathbf{H}$. is then entitled to some repayment of tax for 1943-4 and the income tax authorities will deal with the adjustment accordingly. Admittedly this will mean that he is kept out of his money for some months, but we have gathered that this is in accordance with the statutory regulations, and that the Revenue is not prepared to make repayments in such cases until after the end of the present financial year.

\section{LETTERS, NOTES, ETC.}

\section{Estimation of Dental Caries}

Miss Dorothy Smith, L.D.S., writes from Oxford: I wish to correct the description of me as M.B. I am a dentist, not a doctor. Dr. Neely (July 29 , p. 160) supports my criticism when he speak of a distinguished layman, as however distinguished in other fields a layman may be dental examinations are best carried out by persons long trained in the dental profession; but I must apologize to him for not having known that residence in Oxford disqualified me from any criticism at all.

\section{Infant Feeding : A Correction}

Dr. Sylvia Dickinson (Leeds) writes: In my letter about infant feeding (Aug. 19, p. 255) the meaning of the last sentence of the second paragraph has been altered by the omission of a phrase. After the word " consideration" it should read: "but according to methods that base quantity of feed on age, if any difference, etc."

\section{Concurrent Herpes Zoster and Varicella}

Dr. J. Finlay Alexander (Sevenoaks) writes: I have recently had a case of concurrent herpes zoster and varicella in my own practice. A man of 69 , after feeling out of sorts for a few days, began to have a painful neuralgic headache in the left frontal region, and then developed some "blisters" in the painful area. I saw him first on a Thursday, when he had a well-developed herpes of the supra-orbital branch of the fifth nerve, with considerable swelling of the upper eyelid and many vesicles running into one another extending on to the top of the head. He had a temperature of $101.5^{\circ}$ F., with definite constitutional symptoms. Next day he was 